\title{
Diagnostic Utility of Unenhanced Computed Tomography for Acute Aortic Syndrome
}

\author{
Manabu Kurabayashi, MD; Kaoru Okishige, MD; Daisuke Ueshima, MD; Kojiro Yoshimura, MD; \\ Tsukasa Shimura, MD; Hidetoshi Suzuki, MD; Asano Mitsutoshi, MD; \\ Hideshi Aoyagi, MD; Yoichi Otani, MD; Mitsuaki Isobe, MD
}

\begin{abstract}
Background: The diagnostic value of unenhanced computed tomography (CT) for diagnosing acute aortic dissection $(A A D)$ and ruptured thoracic aortic aneurysm (TAA) remains unclear.

Methods and Results: We examined 219 consecutive patients who visited the emergency room with suspected acute aortic syndrome (AAS) because of chest or back pain and who underwent both unenhanced and contrastenhanced 64-row multi-detector CT. The unenhanced CT findings were evaluated by the cardiologist on duty who was blind to the findings of contrast-enhanced CT. Diagnosis of AAS was confirmed in 103 patients (47\%, 95 AAD and 8 ruptured TAA patients) based on evaluation of both unenhanced and contrast-enhanced CT images, which was used as the reference standard for validating the diagnostic value of the unenhanced CT findings. Sensitivity and specificity of the findings of a high-attenuation crescent, which represents hematoma in the aortic wall, were $61.2 \%$ and $99.1 \%$, respectively. Sensitivity and specificity of linear high density in the aorta, which represents an intimal flap, were $59.2 \%$ and $96.6 \%$, respectively. If unenhanced CT showed none of high-attenuation crescent, linear high density, internal displacement of intimal calcification, or TAA, the negative predictive value was $93.3 \%$.
\end{abstract}

Conclusions: Unenhanced CT is a good tool for ruling AAS in, but the false-negative rate of $6.7 \%$ is high for ruling AAS out because it has to be the minimum possible. (Circ $J$ 2014; 78: 1928-1934)

Key Words: Acute aortic syndrome; Computed tomography; Diagnosis

$\mathbf{C}$ omputed tomography (CT) is the most commonly used imaging modality for patients with suspected acute aortic syndrome (AAS), which includes acute aortic dissection (AAD), variant forms of $\mathrm{AAD}$, and ruptured thoracic aortic aneurysm (TAA). ${ }^{1,2}$ Especially in patients with AAD, contrast-enhanced CT is known to have very high sensitivity and specificity. ${ }^{2-4}$ However, there are occasions when physicians hesitate to administer contrast medium, because of its allergenicity and nephrotoxicity. Unenhanced CT could be a valid alternative in such cases. For example, there are several signs of AAD on unenhanced $\mathrm{CT}$, including high-attenuation crescent (Figure 1), which represents clotted blood in the false lumen, internal displacement of intimal calcification (Figure 1), thoracic aortic aneurismal change, and linear high density (Figure 2), which represents an intimal flap. ${ }^{5-8}$ Unenhanced CT may also identify ruptured TAA, with findings such as aortic aneurysmal change and high-attenuation crescent of the aneurysmal aortic wall. ${ }^{9}$ However, there appear to be few studies that have quantified how well AAS can be diagnosed based solely on unenhanced CT images. Therefore, the aim of our study was to evaluate this question in patients presenting to the emergency room (ER) with chest or back pain.

\section{Study Population}

\section{Methods}

From January 2009 to December 2012, 392 patients visited the ER of the Yokohama City Minato Red Cross Hospital (1 of 8 tertiary medical centers in Yokohama) within 24h of the onset of chest or back pain and were considered to have a low probability of acute coronary syndrome from electrocardiographic and laboratory data. Of these 392 patients, 227 were strongly suspected of having AAS by an experienced emergency physician or cardiologist, and underwent both unenhanced and contrast-enhanced CT; 8 of these patients were excluded from study because of a history of aortic surgery, aortic endovascular treatment, or aortic dissection. The remaining consecutive 219 patients were enrolled in this observational study in a prospective manner.

Received February 14, 2014; revised manuscript received April 16, 2014; accepted April 21, 2014; released online June 9, 2014 Time for primary review: 27 days

Division of Cardiology (M.K., K.O., K.Y., T.S., H.S., A.M., H.A.), Division of Radiology (Y.O.), Yokohama City Minato Red Cross Hospital, Yokohama; Department of Cardiovascular Medicine, Tokyo Medical and Dental University, Tokyo (D.U., M.I.), Japan

Mailing address: Manabu Kurabayashi, MD, Division of Cardiology, Yokohama City Minato Red Cross Hospital, 3-12-1 Shin-Yamashita, Naka-ku, Yokohama 231-8682, Japan. E-mail: kurabayashi.card@yokohama.jrc.or.jp

ISSN-1346-9843 doi:10.1253/circj.CJ-14-0198

All rights are reserved to the Japanese Circulation Society. For permissions, please e-mail: cj@j-circ.or.jp 


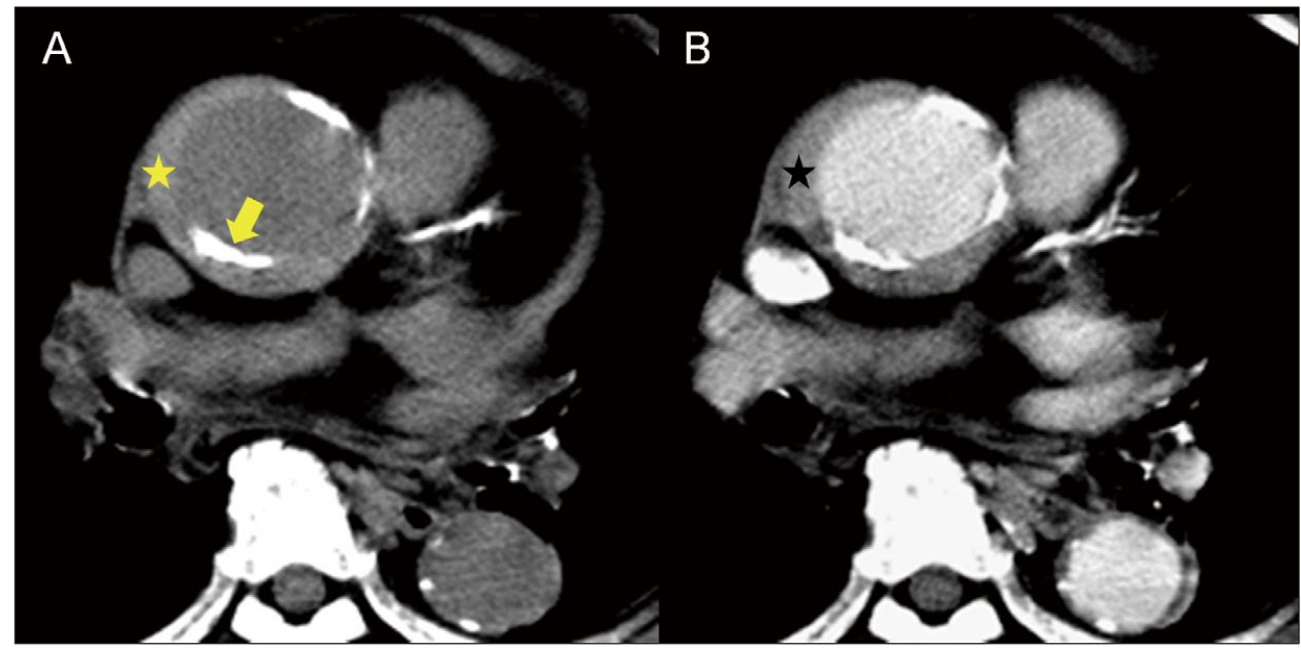

Figure 1. (A) Unenhanced axial computed tomography (CT) image shows internal displacement of intimal calcification (yellow arrow) and a high-attenuation crescent (yellow star). (B) Contrast-enhanced CT image shows a relatively unenhanced crescent area (black star), which is the high-attenuation area on the unenhanced CT image.

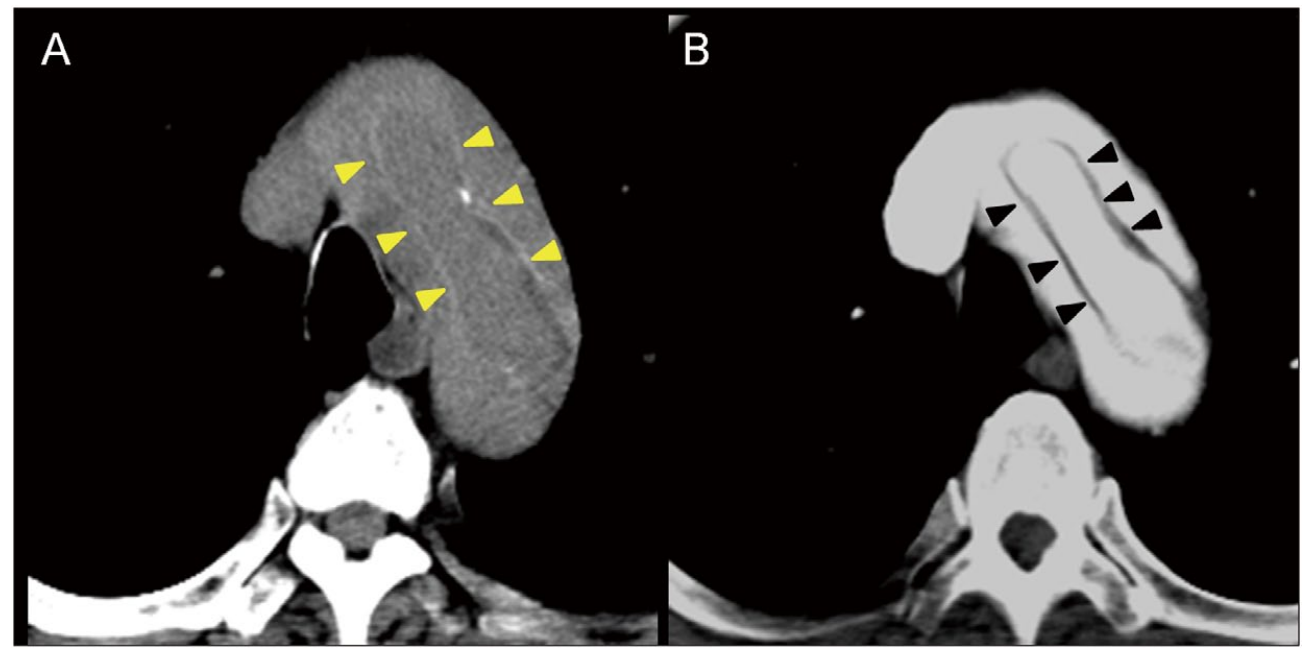

Figure 2. Identification of an intimal flap represented by linear high density. (A) Unenhanced axial computed tomography (CT) image shows linear high density traversing the aortic lumen (yellow arrowheads). (B) Contrast-enhanced CT image confirms that an intimal flap (black arrowheads) separates the true and false lumens of the aorta.

\section{Imaging Technique}

Non-ECG-gated CT scanning was performed using a 64-row scanner (Aquilion 64, Toshiba Medical Systems) with the following parameters: $200 \mathrm{~mA}, 120 \mathrm{kV}$, pitch of $15 \mathrm{~mm}$, and $1-\mathrm{mm}$ collimation. Each scan began with unenhanced imaging from the apex of the lung to the pelvis. Unenhanced CT scans were reconstructed at 5-mm intervals in the transverse plane to match the intervals used for a screening inspection of the chest and the abdomen. Contrast-enhanced CT scans were subsequently performed over the same area. Contrast material (iopamidol, $300 \mathrm{mg} / \mathrm{ml}$ of iodine; total volume, $100 \mathrm{ml}$ ) was injected at a rate of $3-4 \mathrm{ml} / \mathrm{s}$ through a right arm vein using an automated injector. The scan delay of the early phase was $25-35 \mathrm{~s}$, and that of the delayed phase was 120-180s. Contrast-enhanced CT scans were reconstructed at 5-mm intervals in the transverse plane, and at 2-mm intervals in the transverse and obliquesagittal planes parallel to the aortic arch in selected cases.

\section{Definition of Unenhanced CT Findings}

We wanted to evaluate the utility of 4 markers of AAS on unenhanced CT, namely, high-attenuation crescent, linear high density in the aorta, internal displacement of intimal calcification, and TAA. The first of these was defined as a crescentshaped hyperattenuating region of thickening of the aortic wall $(>7 \mathrm{~mm}) .{ }^{10,11}$ A cut-off value of $7 \mathrm{~mm}$ was chosen based on previous studies that had used this value for images ob- 


\begin{tabular}{|c|c|c|c|}
\hline & $\begin{array}{l}\text { Patients with AAS } \\
(n=103)\end{array}$ & $\begin{array}{l}\text { Patients without AAS } \\
\qquad(n=116)\end{array}$ & $P$ value \\
\hline \multicolumn{4}{|l|}{ Baseline characteristics } \\
\hline Age (years) & $69.7 \pm 13.9$ & $60.9 \pm 16.4$ & $<0.001$ \\
\hline Male sex (\%) & $64(62)$ & $69(59)$ & 0.782 \\
\hline History of hypertension (\%) & $59(57)$ & $56(48)$ & 0.223 \\
\hline Diabetes mellitus (\%) & $14(14)$ & $18(16)$ & 0.707 \\
\hline Dyslipidemia (\%) & $26(25)$ & $35(30)$ & 0.453 \\
\hline Current smoker (\%) & $48(47)$ & $47(41)$ & 0.413 \\
\hline Systolic blood pressure $(\mathrm{mmHg})$ & $168 \pm 53$ & $164 \pm 37$ & 0.491 \\
\hline Heart rate (beats/min) & $76 \pm 18$ & $80 \pm 16$ & 0.076 \\
\hline D-dimer >500 ng/ml (\%) & $76 / 76(100)$ & $53 / 56(95)$ & 0.074 \\
\hline $\mathrm{D}-\operatorname{dimer}(\mu \mathrm{g} / \mathrm{ml})$ & $11.1 \pm 12.5$ & $11.0 \pm 34.8$ & 0.970 \\
\hline \multicolumn{4}{|l|}{ Type of AAS } \\
\hline Acute aortic dissection & 95 & - & \\
\hline \multicolumn{4}{|l|}{ Stanford type (\%) } \\
\hline Type A & $34(36)$ & - & \\
\hline Type B & $61(64)$ & - & \\
\hline Status of the false lumen (\%) & & - & \\
\hline Patent & $23(24)$ & - & \\
\hline Partial thrombosis & $18(19)$ & - & \\
\hline Complete thrombosis & $54(57)$ & - & \\
\hline Ruptured TAA (\%) & 8 & - & \\
\hline Acute rupture & $5(62.5)$ & - & \\
\hline Impending rupture & $3(37.5)$ & - & \\
\hline
\end{tabular}

Continuous variables are expressed as mean \pm standard deviation.

AAS, acute aortic syndrome; TAA, thoracic aortic aneurysm.

tained from CT, magnet resonance imaging, and echocardiography. ${ }^{10,12,13}$ Linear high density in the aorta was defined as a linear structure within the aortic lumen with a density higher than that of the aortic lumen. Internal displacement of intimal calcification was defined as internal displacement larger than the normal aortic thickness $(>4 \mathrm{~mm}){ }^{6}$ TAA was defined as a saccular aneurysm regardless of size, or fusiform aneurysm with a maximum diameter $\geq 45 \mathrm{~mm}$.

\section{Diagnostic Criteria and Subset of AAS}

AAD was diagnosed using previously established criteria, namely, by confirming the presence of a true and a false lumen separated by an intimal flap, on contrast-enhanced CT. ${ }^{4,6,7}$ According to the type of false lumen, AAD was further classified as patent, partial thrombosis, or complete thrombosis. ${ }^{14}$ The extent of AAD was based on the Stanford classification.

Ruptured TAA includes impending rupture and acute rupture of a TAA. Impending rupture was confirmed by high-attenuation crescent of the aneurysmal aortic wall without frank aneurysmal leak. Acute rupture was diagnosed by periaortic hemorrhage involving the mediastinum or thoracic cavity with or without high-attenuation crescent of the aneurysmal aortic wall.

\section{Imaging Interpretation and the Diagnostic Value of Unenhanced CT}

The unenhanced CT images were evaluated by an experienced cardiologist on duty who was blind to the findings of contrastenhanced CT. The cardiologist used a uniform questionnaire to document the presence or absence of specific unenhanced CT findings. Subsequently, 2 independent observers (boardcertified radiologist (Y.O.) and board-certified cardiologist
(K.O.)) evaluated the findings of both unenhanced and contrast-enhanced CT, and made judgments regarding the presence or absence of AAS and its type. The rate of independent observer agreement for detection of AAS was $100 \%$, and for distinction of the type of AAS (AAD or ruptured TAA) was $99 \%$ (102 of $103, \kappa>0.80)$. Conflicting results of the evaluation of unenhanced and contrast-enhanced CT for distinction of the type of AAS were resolved by a third blinded observer. The judgments based on unenhanced and contrast-enhanced CT were used as the reference standard for validating the diagnostic value of the unenhanced CT findings in each study patient. This study was approved by the institutional review board of the Yokohama City Minato Red Cross Hospital, and informed written consent was given by each patient before CT.

\section{Statistical Analysis}

The sensitivity, specificity, positive likelihood ratio, negative likelihood ratio, positive predictive value and negative predictive value of unenhanced CT findings were calculated. Continuous variables were compared using Student's t-test, or Welch's t-test. Categorical data were compared using Fisher's exact tests. A P value $<0.05$ was considered statistically significant. All data analysis was carried out using SPSS version 18.0 (SPSS, Inc, Chicago, IL, USA).

\section{Results}

Of 219 patients, $103(47 \%)$ were diagnosed with AAS, of whom 95 patients had AAD and 8 patients had a ruptured TAA. The characteristics of patients with and without AAS are presented in Table 1. Baseline characteristics were comparable between both the patient groups, except that patients with AAS were 


\begin{tabular}{|c|c|c|c|c|c|c|}
\hline & Sensitivity & Specificity & PLR & NLR & PPV & NPV \\
\hline \multicolumn{7}{|c|}{ Internal displacement of intimal calcification } \\
\hline All patients & $\begin{array}{c}76.7 \% \\
(71.1-80.9)\end{array}$ & $\begin{array}{c}89.7 \% \\
(84.6-93.4)\end{array}$ & $\begin{array}{c}7.41 \\
(4.63-12.27)\end{array}$ & $\begin{array}{c}0.26 \\
(0.20-0.34)\end{array}$ & $\begin{array}{c}86.8 \% \\
(80.4-91.6)\end{array}$ & $\begin{array}{c}81.3 \% \\
(76.7-84.6)\end{array}$ \\
\hline AAD patients & $\begin{array}{c}76.8 \% \\
(70.8-81.4)\end{array}$ & $\begin{array}{c}89.7 \% \\
(84.7-93.4)\end{array}$ & $\begin{array}{c}7.43 \\
(4.64-12.25)\end{array}$ & $\begin{array}{c}0.26 \\
(0.20-0.34)\end{array}$ & $\begin{array}{c}85.9 \% \\
(79.2-90.9)\end{array}$ & $\begin{array}{c}82.5 \% \\
(78.0-85.9)\end{array}$ \\
\hline Ruptured TAA patients & $\begin{array}{c}75.0 \% \\
(43.1-92.6)\end{array}$ & $\begin{array}{c}89.7 \% \\
(87.5-90.9)\end{array}$ & $\begin{array}{c}7.25 \\
(3.43-10.15)\end{array}$ & $\begin{array}{c}0.28 \\
(0.08-0.65)\end{array}$ & $\begin{array}{c}33.3 \% \\
(19.1-41.2)\end{array}$ & $\begin{array}{c}98.1 \% \\
(95.7-99.4)\end{array}$ \\
\hline \multicolumn{7}{|l|}{ High-attenuation crescent } \\
\hline All patients & $\begin{array}{c}61.2 \% \\
(57.4-62.0)\end{array}$ & $\begin{array}{c}99.1 \% \\
(95.8-99.8)\end{array}$ & $\begin{array}{c}70.95 \\
(13.59-404.68)\end{array}$ & $\begin{array}{c}0.39 \\
(0.38-0.45)\end{array}$ & $\begin{array}{c}98.4 \% \\
(92.3-99.7)\end{array}$ & $\begin{array}{c}74.2 \% \\
(71.7-74.7)\end{array}$ \\
\hline AAD patients & $\begin{array}{c}60.0 \% \\
(55.9-60.9)\end{array}$ & $\begin{array}{c}99.1 \% \\
(95.8-99.8)\end{array}$ & $\begin{array}{c}69.60 \\
(13.34-397.36)\end{array}$ & $\begin{array}{c}0.40 \\
(0.39-0.46)\end{array}$ & $\begin{array}{c}98.3 \% \\
(91.6-99.7)\end{array}$ & $\begin{array}{c}75.2 \% \\
(72.6-75.7)\end{array}$ \\
\hline Ruptured TAA patients & $\begin{array}{c}75.0 \% \\
(48.1-85.0)\end{array}$ & $\begin{array}{c}99.1 \% \\
(97.3-99.8)\end{array}$ & $\begin{array}{c}87.00 \\
(17.66-493.83)\end{array}$ & $\begin{array}{c}0.25 \\
(0.15-0.53)\end{array}$ & $\begin{array}{c}85.7 \% \\
(54.9-97.1)\end{array}$ & $\begin{array}{c}98.3 \% \\
(96.4-99.0)\end{array}$ \\
\hline \multicolumn{7}{|c|}{ Linear density in aortic lumen } \\
\hline All patients & $\begin{array}{c}59.2 \% \\
(54.5-61.5)\end{array}$ & $\begin{array}{c}96.6 \% \\
(92.3-98.6)\end{array}$ & $\begin{array}{c}17.18 \\
(7.11-44.39)\end{array}$ & $\begin{array}{c}0.42 \\
(0.39-0.49)\end{array}$ & $\begin{array}{c}93.8 \% \\
(86.3-97.5)\end{array}$ & $\begin{array}{c}72.7 \% \\
(69.6-74.3)\end{array}$ \\
\hline AAD patients & $\begin{array}{c}63.2 \% \\
(58.1-65.7)\end{array}$ & $\begin{array}{c}96.6 \% \\
(92.4-98.6)\end{array}$ & $\begin{array}{c}18.32 \\
(7.65-47.19)\end{array}$ & $\begin{array}{c}0.38 \\
(0.35-0.45)\end{array}$ & $\begin{array}{c}93.8 \% \\
(86.2-97.5)\end{array}$ & $\begin{array}{c}76.2 \% \\
(72.9-77.8)\end{array}$ \\
\hline Ruptured TAA patients & $\begin{array}{c}12.5 \% \\
(2.3-36.6)\end{array}$ & $\begin{array}{c}96.6 \% \\
(95.8-98.2)\end{array}$ & $\begin{array}{c}3.63 \\
(0.56-20.54)\end{array}$ & $\begin{array}{c}0.91 \\
(0.65-1.02)\end{array}$ & $\begin{array}{c}20.0 \% \\
(3.7-58.6)\end{array}$ & $\begin{array}{c}94.1 \% \\
(93.4-95.7)\end{array}$ \\
\hline \multicolumn{7}{|l|}{ Thoracic aortic aneurysm } \\
\hline All patients & $\begin{array}{c}44.7 \% \\
(39.4-48.0)\end{array}$ & $\begin{array}{c}94.0 \% \\
(89.3-96.9)\end{array}$ & $\begin{array}{c}7.40 \\
(3.68-15.57)\end{array}$ & $\begin{array}{c}0.59 \\
(0.54-0.68)\end{array}$ & $\begin{array}{c}86.8 \% \\
(76.6-93.3)\end{array}$ & $\begin{array}{c}65.7 \% \\
(62.4-67.7)\end{array}$ \\
\hline AAD patients & $\begin{array}{c}40.0 \% \\
(34.4-43.6)\end{array}$ & $\begin{array}{c}94.0 \% \\
(89.4-96.9)\end{array}$ & $\begin{array}{c}6.63 \\
(3.25-14.09)\end{array}$ & $\begin{array}{c}0.64 \\
(0.58-0.73)\end{array}$ & $\begin{array}{c}84.4 \% \\
(72.7-92.0)\end{array}$ & $\begin{array}{c}65.7 \% \\
(62.5-67.7)\end{array}$ \\
\hline Ruptured TAA patients & $\begin{array}{c}100.0 \% \\
(71.3-100.0)\end{array}$ & $\begin{array}{c}94.0 \% \\
(92.0-94.0)\end{array}$ & $\begin{array}{c}16.57 \\
(8.89-16.57)\end{array}$ & $\begin{array}{c}0.00 \\
(0.00-0.31)\end{array}$ & $\begin{array}{c}53.3 \% \\
(38.0-53.3)\end{array}$ & $\begin{array}{c}100.0 \% \\
(97.9-100.0)\end{array}$ \\
\hline
\end{tabular}

Data in parentheses are 95\% confidence interval. AAD, acute aortic dissection; CT, computed tomography; NLR, negative likelihood ratio; NPV, negative predictive value; PLR, positive likelihood ratio; PPV, positive predictive value. Other abbreviations as in Table 1.

\begin{tabular}{|lcccccc|}
\hline \multicolumn{2}{|c|}{ Table 3. Diagnostic Value of the Combination of the Unenhanced CT Findings in Patients With Suspected AAS } \\
& Sensitivity & Specificity & PLR & NLR & PPV & NPV \\
\#Any of the four unenhanced CT findings & $93.2 \%$ & $83.6 \%$ & 5.69 & 0.08 & $83.5 \%$ & $93.3 \%$ \\
& $(88.2-96.4)$ & $(79.2-86.5)$ & $(4.24-7.12)$ & $(0.04-0.15)$ & $(79.0-86.3)$ & $(88.3-96.4)$ \\
\hline
\end{tabular}

Data in parentheses are $95 \%$ confidence interval.

\#The four unenhanced findings include internal displacement of intimal calcification, high-attenuation crescent, linear high density in aortic lumen, and thoracic aortic aneurysm.

Abbreviations as in Tables 1,2.

older than patients without AAS. There was no significant difference in the positive rate of D-dimer $(>500 \mathrm{ng} / \mathrm{ml})$ or the average value of D-dimer between both groups. Of the 95 AAD patients, 2 patients had a concomitant penetrating atherosclerotic ulcer. With regard to the Stanford classification of AAD, 34 patients (36\%) were Stanford type A and 61 patients (64\%) were Stanford type B. With respect to the status of the false lumen, 23 patients $(24 \%)$ had the patent type, 18 patients $(19 \%)$ had the partial thrombosis type, and 54 patients (57\%) had complete thrombosis type false lumen. Of the 8 ruptured TAA patients, 3 were impending ruptures and 5 were acute ruptures. Of the 116 non-AAS patients, final diagnoses were abdominal diseases (18 patients, 16\%), acute coronary syndrome (12 patients, $10 \%)$, orthopedic diseases ( 9 patients, $8 \%$ ), other cardiovascular diseases ( 6 patients, $5 \%)$, pulmonary diseases $(5$ patients, $4 \%$ ), and in 66 patients (57\%), the diagnosis was uncertain. Concerning radiation exposure, the dose-length product was $3,121 \pm 907 \mathrm{mGy} \cdot \mathrm{cm}$ in this study.

The sensitivity, specificity, positive and negative likelihood ratios, positive and negative predictive values of the unenhanced CT findings for AAS patients vs. non-AAS patients are presented in Table 2. In general, a likelihood ratio $>10 \quad(<0.1)$ indicates that the test result has a large effect on increasing (decreasing) the probability of disease presence. A likelihood ratio of 5-10 $(0.1-0.2)$ indicates that the test has a moderate effect on increasing (decreasing) the probability of disease presence. ${ }^{15}$ Presence of high-attenuation crescent was able to rule in AAS with a high specificity of $99.1 \%$, a high positive predictive value of $98.4 \%$, and a high positive likelihood ratio of 70.95. Linear density also could rule in AAS with a high specificity of $96.6 \%$, a positive predictive value of $93.8 \%$, and a high positive likelihood ratio of 17.18 . Because none of the 4 unenhanced CT findings had high negative predictive value nor low negative likelihood ratios, individually they were found not to have good properties for ruling out AAS.

The diagnostic value of the combined unenhanced CT findings for diagnosing AAS is presented in Table 3. If an unenhanced CT scan showed none of the 4 signs of high-attenuation 


\begin{tabular}{|c|c|c|c|c|c|c|}
\hline Internal displacement of & Sensitivity & Specificity & PLR & NLR & PPV & NPV \\
\hline All AAD patients & $\begin{array}{c}76.8 \% \\
(70.8-81.4)\end{array}$ & $\begin{array}{c}89.7 \% \\
(84.7-93.4)\end{array}$ & $\begin{array}{c}7.43 \\
(4.64-12.25)\end{array}$ & $\begin{array}{c}0.26 \\
(0.20-0.34)\end{array}$ & $\begin{array}{c}85.9 \% \\
(79.2-90.9)\end{array}$ & $\begin{array}{c}82.5 \% \\
(78.0-85.9)\end{array}$ \\
\hline \multicolumn{7}{|l|}{ Stanford type } \\
\hline Type A & $\begin{array}{c}82.4 \% \\
(69.8-90.8)\end{array}$ & & $\begin{array}{c}7.96 \\
(4.98-11.52)\end{array}$ & $\begin{array}{c}0.20 \\
(0.10-0.35)\end{array}$ & $\begin{array}{c}70.0 \% \\
(59.3-77.1)\end{array}$ & $\begin{array}{c}94.5 \% \\
(90.7-97.1)\end{array}$ \\
\hline Type B & $\begin{array}{c}73.8 \% \\
(65.2-80.4)\end{array}$ & & $\begin{array}{c}7.13 \\
(4.39-11.67)\end{array}$ & $\begin{array}{c}0.29 \\
(0.21-0.41)\end{array}$ & $\begin{array}{c}78.9 \% \\
(69.8-86.0)\end{array}$ & $\begin{array}{c}86.7 \% \\
(82.3-90.0)\end{array}$ \\
\hline \multicolumn{7}{|l|}{ Status of false lumen } \\
\hline Patent & $\begin{array}{c}65.2 \% \\
(48.1-79.0)\end{array}$ & & $\begin{array}{c}6.30 \\
(3.50-10.36)\end{array}$ & $\begin{array}{c}0.39 \\
(0.23-0.60)\end{array}$ & $\begin{array}{c}55.6 \% \\
(40.9-67.3)\end{array}$ & $\begin{array}{c}92.9 \% \\
(89.3-95.7)\end{array}$ \\
\hline Partial thrombosis & $\begin{array}{c}88.9 \% \\
(70.2-96.8)\end{array}$ & & $\begin{array}{c}8.59 \\
(5.31-10.62)\end{array}$ & $\begin{array}{c}0.12 \\
(0.04-0.34)\end{array}$ & $\begin{array}{c}57.1 \% \\
(45.2-62.2)\end{array}$ & $\begin{array}{c}98.1 \% \\
(94.9-99.5)\end{array}$ \\
\hline Complete thrombosis & $\begin{array}{c}77.8 \% \\
(68.6-84.7)\end{array}$ & & $\begin{array}{c}7.52 \\
(4.68-11.91)\end{array}$ & $\begin{array}{c}0.25 \\
(0.17-0.37)\end{array}$ & $\begin{array}{c}77.8 \% \\
(68.6-84.7)\end{array}$ & $\begin{array}{c}89.7 \% \\
(85.4-92.9)\end{array}$ \\
\hline \multicolumn{7}{|l|}{ High-attenuation crescent } \\
\hline All AAD patients & $\begin{array}{c}60.0 \% \\
(55.9-60.9)\end{array}$ & $\begin{array}{c}99.1 \\
(95.8-99.8)\end{array}$ & $\begin{array}{c}69.60 \\
(13.34-397.36)\end{array}$ & $\begin{array}{c}0.40 \\
(0.39-0.46)\end{array}$ & $\begin{array}{c}98.3 \% \\
(91.6-99.7)\end{array}$ & $\begin{array}{c}75.2 \% \\
(72.6-75.7)\end{array}$ \\
\hline \multicolumn{7}{|l|}{ Stanford type } \\
\hline Type A & $\begin{array}{c}52.9 \% \\
(43.4-55.4)\end{array}$ & & $\begin{array}{c}61.41 \\
(11.85-358.05)\end{array}$ & $\begin{array}{c}0.48 \\
(0.44-0.59)\end{array}$ & $\begin{array}{c}94.7 \% \\
(77.6-99.1)\end{array}$ & $\begin{array}{c}87.8 \% \\
(85.3-88.4)\end{array}$ \\
\hline Type B & $\begin{array}{c}63.9 \% \\
(58.0-65.3)\end{array}$ & & $\begin{array}{c}74.16 \\
(14.55-424.71)\end{array}$ & $\begin{array}{c}0.36 \\
(0.35-0.44)\end{array}$ & $\begin{array}{c}97.5 \% \\
(88.4-99.6)\end{array}$ & $\begin{array}{c}83.9 \% \\
(81.3-84.5)\end{array}$ \\
\hline \multicolumn{7}{|l|}{ Status of false lumen } \\
\hline Patent & $\begin{array}{c}0.0 \% \\
(0.0-0.3)\end{array}$ & & $\begin{array}{c}0.00 \\
(0.00-19.21)\end{array}$ & $\begin{array}{c}1.01 \\
(0.97-1.01)\end{array}$ & $\begin{array}{c}0.0 \% \\
(0.0-79.2)\end{array}$ & $\begin{array}{c}83.3 \% \\
(83.3-83.9)\end{array}$ \\
\hline Partial thrombosis & $\begin{array}{c}61.1 \% \\
(45.7-65.7)\end{array}$ & & $\begin{array}{c}70.89 \\
(14.02-418.01)\end{array}$ & $\begin{array}{c}0.39 \\
(0.34-0.56)\end{array}$ & $\begin{array}{c}91.7 \% \\
(68.5-98.5)\end{array}$ & $\begin{array}{c}94.3 \% \\
(92.0-94.9)\end{array}$ \\
\hline Complete thrombosis & $\begin{array}{c}85.2 \% \\
(79.1-86.7)\end{array}$ & & $\begin{array}{c}98.82 \\
(21.36-557.94)\end{array}$ & $\begin{array}{c}0.15 \\
(0.13-0.22)\end{array}$ & $\begin{array}{c}97.9 \% \\
(90.9-99.6)\end{array}$ & $\begin{array}{c}93.5 \% \\
(90.8-94.2)\end{array}$ \\
\hline \multicolumn{7}{|c|}{ Linear high density in aortic lumen } \\
\hline All AAD patients & $\begin{array}{c}63.2 \% \\
(58.1-65.7)\end{array}$ & $\begin{array}{c}96.6 \% \\
(92.4-98.6)\end{array}$ & $\begin{array}{c}18.32 \\
(7.65-47.19)\end{array}$ & $\begin{array}{c}0.38 \\
(0.35-0.45)\end{array}$ & $\begin{array}{c}93.8 \% \\
(86.2-97.5)\end{array}$ & $\begin{array}{c}76.2 \% \\
(72.9-77.8)\end{array}$ \\
\hline \multicolumn{7}{|l|}{ Stanford type } \\
\hline Type A & $\begin{array}{c}73.5 \% \\
(62.3-80.1)\end{array}$ & & $\begin{array}{c}21.32 \\
(9.23-52.93)\end{array}$ & $\begin{array}{c}0.27 \\
(0.20-0.41)\end{array}$ & $\begin{array}{c}86.2 \% \\
(73.0-93.9)\end{array}$ & $\begin{array}{c}92.6 \% \\
(89.4-94.4)\end{array}$ \\
\hline Type B & $\begin{array}{c}57.4 \% \\
(50.1-61.2)\end{array}$ & & $\begin{array}{c}16.64 \\
(6.86-43.38)\end{array}$ & $\begin{array}{c}0.44 \\
(0.39-0.54)\end{array}$ & $\begin{array}{c}89.7 \% \\
(78.3-95.8)\end{array}$ & $\begin{array}{c}81.2 \% \\
(77.9-82.9)\end{array}$ \\
\hline \multicolumn{7}{|l|}{ Status of false lumen } \\
\hline Patent & $\begin{array}{c}47.8 \% \\
(33.2-57.6)\end{array}$ & & $\begin{array}{c}13.87 \\
(5.24-38.20)\end{array}$ & $\begin{array}{c}0.54 \\
(0.43-0.71)\end{array}$ & $\begin{array}{c}73.3 \% \\
(51.0-88.3)\end{array}$ & $\begin{array}{c}90.3 \% \\
(87.6-92.1)\end{array}$ \\
\hline Partial thrombosis & $\begin{array}{c}72.2 \% \\
(54.4-83.6)\end{array}$ & & $\begin{array}{c}20.94 \\
(8.74-49.45)\end{array}$ & $\begin{array}{c}0.29 \\
(0.17-0.49)\end{array}$ & $\begin{array}{c}76.5 \% \\
(57.6-88.5)\end{array}$ & $\begin{array}{c}95.7 \% \\
(93.0-97.5)\end{array}$ \\
\hline Complete thrombosis & $\begin{array}{c}66.7 \% \\
(58.7-71.0)\end{array}$ & & $\begin{array}{c}19.33 \\
(8.18-49.63)\end{array}$ & $\begin{array}{c}0.35 \\
(0.29-0.45)\end{array}$ & $\begin{array}{c}90.0 \% \\
(79.2-95.9)\end{array}$ & $\begin{array}{c}86.2 \% \\
(82.8-88.0)\end{array}$ \\
\hline \multicolumn{7}{|l|}{ Thoracic aortic aneurysm } \\
\hline All AAD patients & $\begin{array}{c}40.0 \% \\
(34.4-43.6)\end{array}$ & $\begin{array}{c}94.0 \% \\
(89.4-96.9)\end{array}$ & $\begin{array}{c}6.63 \\
(3.25-14.09)\end{array}$ & $\begin{array}{c}0.64 \\
(0.58-0.73)\end{array}$ & $\begin{array}{c}84.4 \% \\
(72.7-92.0)\end{array}$ & $\begin{array}{c}65.7 \% \\
(62.5-67.7)\end{array}$ \\
\hline \multicolumn{7}{|l|}{ Stanford type } \\
\hline Type A & $\begin{array}{c}73.5 \% \\
(61.3-82.1)\end{array}$ & & $\begin{array}{c}12.19 \\
(6.38-23.29)\end{array}$ & $\begin{array}{c}0.28 \\
(0.19-0.43)\end{array}$ & $\begin{array}{c}78.1 \% \\
(65.2-87.2)\end{array}$ & $\begin{array}{c}92.4 \% \\
(88.9-94.8)\end{array}$ \\
\hline Type B & $\begin{array}{c}21.3 \% \\
(14.6-26.7)\end{array}$ & & $\begin{array}{c}3.53 \\
(1.53-8.28)\end{array}$ & $\begin{array}{c}0.84 \\
(0.76-0.94)\end{array}$ & $\begin{array}{c}65.0 \% \\
(44.6-81.3)\end{array}$ & $\begin{array}{c}69.4 \% \\
(66.8-71.5)\end{array}$ \\
\hline \multicolumn{7}{|l|}{ Status of false lumen } \\
\hline Patent & $\begin{array}{c}34.8 \% \\
(20.8-47.7)\end{array}$ & & $\begin{array}{c}5.76 \\
(2.36-13.78)\end{array}$ & $\begin{array}{c}0.69 \\
(0.54-0.87)\end{array}$ & $\begin{array}{c}53.3 \% \\
(31.9-73.2)\end{array}$ & $\begin{array}{c}87.9 \% \\
(85.3-90.3)\end{array}$ \\
\hline Partial thrombosis & $\begin{array}{c}50.0 \% \\
(31.9-65.5)\end{array}$ & & $\begin{array}{c}8.29 \\
(3.61-18.06)\end{array}$ & $\begin{array}{c}0.53 \\
(0.36-0.75)\end{array}$ & $\begin{array}{c}56.3 \% \\
(35.9-73.7)\end{array}$ & $\begin{array}{c}92.4 \% \\
(89.6-94.7)\end{array}$ \\
\hline Complete thrombosis & $\begin{array}{c}38.9 \% \\
(30.4-45.0)\end{array}$ & & $\begin{array}{c}6.44 \\
(3.04-14.09)\end{array}$ & $\begin{array}{c}0.65 \\
(0.57-0.77)\end{array}$ & $\begin{array}{c}75.0 \% \\
(58.7-86.8)\end{array}$ & $\begin{array}{c}76.8 \% \\
(73.5-79.1)\end{array}$ \\
\hline
\end{tabular}

Data in parentheses are 95\% confidence interval. Abbreviations as in Tables 1,2. 
crescent, linear high density, internal displacement of intimal calcification, and TAA, the negative likelihood ratio was 0.08 and the negative predictive value was $93.3 \%$.

The diagnostic value of unenhanced $\mathrm{CT}$ for diagnosing AAD (ie, excluding ruptured TAA) is presented in Table 4. Highattenuation crescent had good rule-in properties for all types of $\mathrm{AAD}$, with the exception of the patent false lumen type in which the false lumen did not contain thrombus. Linear high density had a good rule-in property regardless of the Stanford classification and the status of false lumen. Again, none of the unenhanced CT findings had good properties for ruling out AAD.

\section{Discussion}

The present study demonstrated that unenhanced CT could reliably rule in AAS based on diagnostic findings such as highattenuation crescent and linear high density, which had high positive predictive values of $>90 \%$, and high positive likelihood ratios of $>10$. With regard to ruling out AAS, the individual unenhanced CT findings did not have good properties: they had negative likelihood ratios $>0.10$. However, if a patient had none of the 4 markers, the negative predictive value was $93.3 \%$ (equivalent to a false-negative rate of $6.7 \%$ ) and the negative likelihood ratio was 0.08 . In most diagnostic tests, a false-negative rate of $6.7 \%$ would be considered quite low, but the dire consequences of AAS require a low threshold. This is especially true in light of the fact that the sensitivity and specificity of enhanced CT for diagnosing AAD are nearly 100\%.2,16 Nevertheless, we believe it is of great benefit to know the predictive value of unenhanced CT because of the small number of patients in whom contrast injection should be avoided, and for whom the physician can make informed risk assessment weighting the probabilities of underdiagnosing AAS against the possible consequences of contrast injection in compromised patients.

The identification of an intimal flap and a true and a false aortic lumen are definitive signs of aortic dissection. In general, contrast medium injection is required to demonstrate the presence of the intimal flap by CT. ${ }^{6,7}$ Demos et al reported that unenhanced CT could be used to detect the intimal flap of aortic dissection. ${ }^{5}$ Because the density of the aortic wall of patients with AAD is frequently high because of atherosclerosis, the contrast between the density of the aortic wall and the aortic lumen could be large. If the density contrast is large, the intimal flap of aortic dissection is visible on unenhanced CT. In the present study, linear high density representing the flap had a high positive predictive value of $93.8 \%$, and a high positive likelihood ratio of 18.32 , which could reliably rule in AAD. Linear high density was not a good rule-in parameter for ruptured TAA, as expected, because TAA lacks an intimal flap.

High-attenuation crescent reflects clotted blood in the aortic wall and had favorable rule-in properties for AAS in the present study. Its diagnostic value depends on the status of the aortic wall, because it does not have any sensitivity in patients with the patent type of false lumen AAD in which the false lumen does not contain thrombus. On the other hand, high-attenuation crescent could be useful for distinguishing AAS in which the aortic wall contains fresh thrombus from stable aortic aneurysm containing chronic thrombus. On the unenhanced CT, fresh thrombus of thrombosed AAD or ruptured TAA showed high-attenuation crescent, whereas the chronic thrombus of stable aortic aneurysm did not show high attenuation. Furthermore, it has been found that high-attenuation crescent extending longitudinally on unenhanced CT images is evidence of hematoma in a false lumen and allows the diagnosis of AAD. ${ }^{5,17}$ Unenhanced CT is also useful for distinguishing between thrombosed false lumen of AAD and hematoma of ruptured aneurysmal wall.

In aortic dissection, a blood-filled false lumen divides the medial layer of the aorta and displaces the calcified intima inward. Similarly, in ruptured TAA, acute hematoma within the aneurysmal wall could displace the calcified intima inward. Internal displacement of intimal calcification may be simulated by the volume averaging effect at the aortic arch or bends in the aorta, non-vascular pathologic structures contiguous with the aortic wall, and calcification of the surface of a blood clot in an aortic aneurysm..$^{5}$ In the present study, internal displacement of intimal calcification was occasionally false positive for non-AAS patients. This may be because the unenhanced CT scans were reconstructed at 5-mm intervals in transverse planes. If the scans had been reconstructed at smaller intervals, the internal displacement of intimal calcification might have had a higher specificity for AAS. However, the internal displacement of intimal calcification had a relatively high specificity and specificity regardless of the type of AAS.

A recent study reported that TAA might be associated with development of AAD because of the findings of a high frequency of $\mathrm{AAD}$ patients with ulcer-like projections or intimal tears contiguous with a TAA. ${ }^{18}$ In the present study, $40 \%$ (38 of 95 patients) with AAD were found to have TAA, a proportion found to be even higher at $73.5 \%$ ( 25 of 34 patients) when limited to patients with Stanford A type AAD. This suggests that thoracic aortic enlargement is associated with not only aortic rupture but also with aortic dissection.

As mentioned, diagnostic accuracy of CT for diagnosing AAD is very high. Some studies conducted before widespread use of ECG-gated CT demonstrated that motion artifact of the ascending aorta was not a major diagnostic problem.,19 However, Reymond et al recently reported that there were 2 main reason for false-positive diagnoses, namely, motion artifact of the ascending aorta arising from non-ECG-gated CT imaging, and the presence of complex anatomy following prior surgical or endovascular aortic repair. ${ }^{20}$ They also mentioned that the vast majority of hospitals did not have around-the-clock access to ECG-gated CT capabilities in the ER. This was true of the ER in the present study, so the ER patients did not undergo ECG-gated CT. Nevertheless, diagnoses of all the cases of Stanford type A aortic dissection were confirmed either at surgery or on follow-up CT, which was ECG-gated CT performed in the institution's department of radiology. Because a major disadvantage of ECG-gated CT is increased radiation exposure, it is arguable whether ECG-gating should be used routinely for undifferentiated patients with chest or back pain. One strategy may be to perform ECG-gated enhanced CT with its increased diagnostic accuracy only when unenhanced CT shows several signs of AAS, and to perform non-ECG-gated enhanced $\mathrm{CT}$, which leads to much less radiation exposure, when the unenhanced CT shows no sign of AAS.

\section{Study Limitations}

First, unenhanced CT was useful in confirming whether patients have AAS or not, but could not provide information regarding the type of AAS, the extent of $\mathrm{AAD}$, the status of false lumen of AAD, or blood flow in aortic branches. This means that if a patient is found to have AAS based on unenhanced CT, he or she will have to undergo contrast-enhanced CT anyway to evaluate the therapeutic options, including emergency surgery. ${ }^{21}$ Second, the positive predictive value of the unenhanced CT findings was relatively high (eg, 83.5\%) when 
all 4 markers were combined. This may have been partially related to a high prevalence of AAS in our study, because it is known that a positive predictive value is not independent of prevalence and high prevalence increases the positive predictive value. However, the most balanced assessment can be made by considering that combining the unenhanced $\mathrm{CT}$ signs showed a good positive likelihood ratio (ie, positive likelihood ratio $>10$ ), which is a parameter that does not depend on the prevalence of a disease. Third, 95 patients may not have been a large enough population to subtype the AAD and provide reliable sensitivity and specificity values. Fourth, the fact that evaluation of unenhanced CT was performed by only one observer, whoever happened to be on call, may be considered a limitation. However, we believe that this was realistic and similar to the ordinary situation in which a cardiologist or emergency physician in the ER must judge promptly whether a patient has AAS or not.

\section{Conclusions}

In patients with suspected AAS, including AAD and ruptured TAA, unenhanced CT is able to rule in AAS by findings such as high-attenuation crescent and linear high density. However, in patients whose unenhanced CTs show neither of these, nor internal displacement of intimal calcification, nor TAA change, the false-negative rate was $6.7 \%$, which may be considered too high relative to the dire consequences of missing AAS, except in select patients in whom contrast agents need to be avoided.

\section{Disclosures}

Grant: None.

\section{References}

1. Hagan PG, Nienaber CA, Isselbacher EM, Bruckman D, Karavite DJ, Russman PL, et al. The International Registry of Acute Aortic Dissection (IRAD): New insights into an old disease. JAMA 2000; 283: 897-903.

2. Yoo SM, Lee HY, White CS. MDCT evaluation of acute aortic syndrome. Radiol Clin North Am 2010; 48: 67-83.

3. Shiga T, Wajima Z, Apfel CC, Inoue T, Ohe Y. Diagnostic accuracy of transesophageal echocardiography, helical computed tomography, and magnetic resonance imaging for suspected thoracic aortic dissection: Systematic review and meta-analysis. Arch Intern Med 2006; 166: $1350-1356$

4. Yoshida S, Akiba H, Tamakawa M, Yama N, Hareyama M, Morishita $\mathrm{K}$, et al. Thoracic involvement of type A aortic dissection and intramural hematoma: Diagnostic accuracy--comparison of emergency helical CT and surgical findings. Radiology 2003; 228: 430-435.

5. Demos TC, Posniak HV, Churchill RJ. Detection of the intimal flap of aortic dissection on unenhanced CT images. Am J Radiol 1986; 146: $601-603$.

6. Erbel R, Alfonso F, Boileau C, Dirsch O, Eber B, Haverich A, et al; Task Force on Aortic Dissection, European Society of Cardiology. Diagnosis and management of aortic dissection. Eur Heart J 2001; 22: $1642-1681$.

7. Hiratzka LF, Bakris GL, Beckman JA, Bersin RM, Carr VF, Casey DE Jr, et al. 2010 ACCF/AHA/AATS/ACR/ASA/SCA/SCAI/SIR/ STS/SVM Guidelines for the diagnosis and management of patients with thoracic aortic disease. J Am Coll Cardiol 2010; 55: e27-e129, doi:10.1016/j.jacc.2010.02.015.

8. JCS Joint Working Group. Guidelines for diagnosis and treatment of aortic aneurysm and aortic dissection (JCS 2011): Digest version. Circ J 2013; 77: 789-828.

9. Mehard WB, Heiken JP, Sicard GA. High-attenuating crescent in abdominal aortic aneurysm wall at CT: A sign of acute or impending rupture. Radiology 1994; 192: 359-362.

10. Chao CP, Walker TG, Kalva SP. Natural history and CT appearances of aortic intramural hematoma. Radiographics 2009; 29: 791 804.

11. Yamada T, Tada S, Harada J. Aortic dissection without intimal rupture: Diagnosis with MR imaging and CT. Radiology 1988; 168: 347-352.

12. Mohr-Kahaly S, Erbel R, Kearney P, Puth M, Meyer J. Aortic intramural hemorrhage visualized by transesophageal echocardiography: Findings and prognostic implication. J Am Coll Cardiol 1994; 23: $658-664$.

13. Ninaber CA, von Kodolitsch Y, Peterren B, Loose R, Helmchen U, Haverich A, et al. Intramural hemorrhage of the thoracic aorta: Diagnostic and therapeutic implications. Circulation 1995; 92: 14651472.

14. Tsai TT, Evangelista A, Nienaber CA, Myrmel T, Meinhardt G, Cooper JV, et al. Partial thrombosis of the false lumen in patients with acute type B aortic dissection. N Engl J Med 2007; 357: 349-359.

15. Jaeschke R, Guyatt GH, Sackett DL. Users' guides to the medical literature. III: How to use an article about a diagnostic test. B: What are the results and will they help me in caring for my patients? The Evidence-Based Medicine Working Group. JAMA 1994; 271: 703 707.

16. Sebastià C, Pallisa E, Quiroga S, Alvarez-Castells A, Dominguez R, Evangelista A. Aortic dissection: Diagnosis and follow-up with helical CT. Radiographics 1999; 19: 45-60.

17. Madureira AJ. Diagnostic criteria for intramural hematoma. Radiology 2002; 222: $576-577$.

18. Tamori Y, Akutsu K, Kasai S, Sakamoto S, Okajima T, Yoshimuta $\mathrm{T}$, et al. Coexistent true aortic aneurysm as a cause of acute aortic dissection. Circ J 2009; 73: 822-825.

19. Hayter RG, Rhea JT, Small A, Tafazoli FS, Novelline RA. Suspected aortic dissection and other aortic disorders: Multi-detector row CT in 373 cases in the emergency setting. Radiology 2006; 238: 841-852.

20. Raymond CE, Aggarwal B, Schoenhagen P, Kralovic DM, Kormos $\mathrm{K}$, Holloway D, et al. Prevalence and factors associated with false positive suspicion of acute aortic syndrome: Experience in a patient population transferred to a specialized aortic treatment center. Cardiovasc Diagn Ther 2013; 3: 196-204.

21. Murashita T, Ogino H, Matsuda H, Sasaki H, Tanaka H, Iba Y, et al. Clinical outcome of emergency surgery for complicated acute type B aortic dissection. Circ J 2012; 76: 650-654. 